\title{
Mídia e Crack: Promovendo Saúde ou Reforçando Relações de Dominação?
}

Media And Crack: Promoting Health Or Reinforcing Relations Of Domination?

Medios Y Crack: ¿Promoviendo Salud O Reforzando Relaciones De Dominación?

Moises Romanini \& Adriane Roso

Universidade Federal de Santa Maria

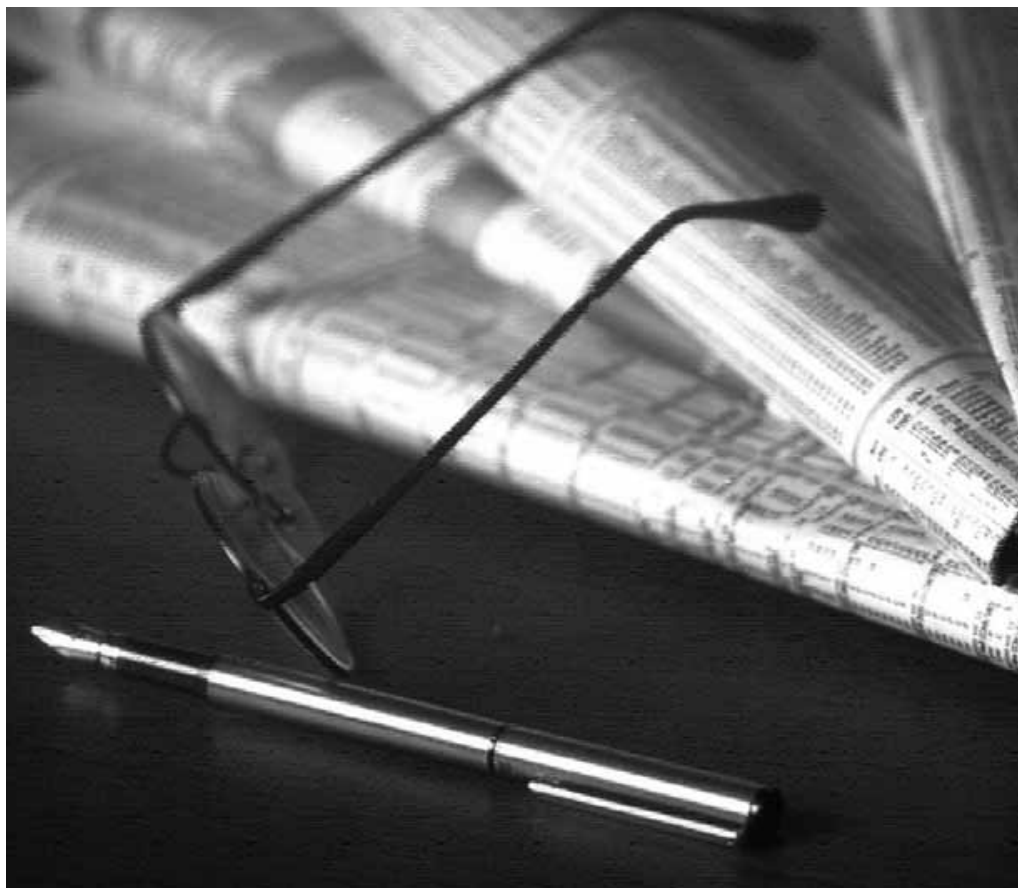


Resumo: Este artigo é baseado na análise discursiva de reportagens veiculadas no jornal de maior circulação do Estado do Rio Grande do Sul, Brasil. Aqui nós examinamos a ideologia subjacente a uma série especial sobre a epidemia do crack. A abordagem teórica e metodológica aplicada foi a hermenêutica de profundidade. A análise ideológica indicou como a série de reportagens serviu para estabelecer e/ou sustentar relações de dominação. Diversas estratégias ideológicas foram identificadas ao longo da série de reportagens analisada: universalização, naturalização, diferenciação, expurgo do outro, padronização e eufemização, entre outras. Essas estratégias operam em conjunto, obscurecendo significados importantes para a compreensão do fenômeno em questão.

Palavras-chave: Psicologia social. Meios de comunicação. Drogas. Cocaína crack.

Abstract: This paper is based on a discursive analysis of reports from the highest circulating mass print media available in the State of Rio Grande do Sul, Brazil. Here we examine the ideology underlying a specific series on "crack epidemics". Depth hermeneutics were used for the theoretical and methodologic approach applied to the analysis. The results of the ideologic analysis indicated how relations of domination were established and/or sustained in the specific series. Several ideologic strategies were identified in the series of reports examined: universalization, naturalization, differentiation, purging of the other, standardization and euphemization, among others. These strategies work together obscuring important meanings for understanding the phenomenon in question.

Keywords: Social psychology. Media. Drugs. Cocaine crack.

Resumen: Ese artículo está basado en el análisis discursivo de reportajes vehiculados en el periódico de mayor circulación del Estado de Rio Grande do Sul, Brasil. Aquí nosotros examinamos la ideología subyacente a una serie especial sobre la "epidemia del crack". El abordaje teórico y metodológico aplicado fue la Hermenéutica de Profundidad. El análisis ideológico indicó cómo la serie de reportajes sirvió para establecer y/o sustentar relaciones de dominación. Diversas estrategias ideológicas fueron identificadas a lo largo de la serie de reportajes analizada: universalización, naturalización, diferenciación, expurgación del otro, estandarización, eufemización, entre otras. Esas estrategias operan en conjunto, obscureciendo significados importantes para la comprensión del fenómeno en cuestión.

Palabras clave: Psicología Social. Medios de comunicación. Drogas. Cocaína crack.

A midiatização da cultura é uma característica fundamentalmente constitutiva das sociedades modernas. Trata-se de um processo através do qual a transmissão das formas simbólicas se tornou sempre mais realizada pelos aparatos das indústrias da mídia (Thompson, 2007). Ela provoca mudanças na forma como as pessoas se relacionam e no conteúdo e na maneira como as mensagens são transmitidas pela mídia, fazendo com que o conhecimento que temos dos fatos que acontecem além do nosso meio social imediato seja derivado da recepção das formas simbólicas (ações e falas, imagens e textos) veiculadas pelos meios de comunicação (Thompson, 2007; Guareschi, 2003).

A ampla circulação de mensagens veiculadas pela mídia fez com que a comunicação de massa se tornasse um fator importante de transmissão da ideologia nas sociedades modernas. Ideologia, segundo John
Thompson, refere-se às "maneiras como o sentido, mobilizado pelas formas simbólicas, serve para estabelecer e sustentar relações de dominação" (Thompson, 2007, p.79).

Essa concepção de ideologia, portanto, apresenta um aspecto constitutivo fundamental: o contexto social estruturado. Considerar os contextos sociais como estruturados implica o reconhecimento da existência de diferenças sistemáticas em relação à distribuição e ao acesso a recursos de vários tipos. $\mathrm{O}$ acesso a esses recursos disponíveis em um contexto determina a localização social das pessoas, e essa localização e as qualificações associadas a essas posições fornecem a esses indivíduos diferentes graus de poder, que é considerado por Thompson como a capacidade que a pessoa tem de agir na busca dos seus objetivos, ou seja, ela tem o poder de agir, de intervir em uma sequência de eventos e de alterar seu curso. 
Um dos primeiros estudos que focou a mídia e sua relação com o crack mostrou que reportagens publicadas em jornais americanos sobre a epidemia do crack eram sensacionalistas, sem embasamento científico e contribuíam para desviar o foco das autoridades de outros problemas sociais mais urgentes (Hartman \& Gollub, 1999).
Assim, a capacidade de agir na busca dos próprios objetivos e interesses depende da posição que o indivíduo ocupa dentro de um campo ou instituição. O poder, então, capacita ou possibilita algumas pessoas a tomarem decisões e a realizarem seus interesses. Sem essa capacidade oferecida por sua posição dentro de um campo ou instituição, os indivíduos não conseguem levar adiante sua trajetória. Nessa perspectiva, ocorre dominação quando as relações de poder dentro dos campos ou instituições são estabelecidas de forma sistematicamente assimétricas (Thompson, 2007). Relações de poder são sistematicamente assimétricas quando um indivíduo ou um grupo de indivíduos detém o poder de maneira estável, excluindo outros indivíduos ou grupos das decisões e das escolhas sobre suas próprias trajetórias.

Constata-se, nesse panorama da midiatização da cultura moderna, que, atualmente, a questão do uso do crack entrou na pauta das discussões de saúde e de segurança pública, principalmente através dos meios de comunicação. O uso inadequado de substâncias psicoativas tem sido apresentado como uma grave ameaça à saúde de inúmeros brasileiros e relacionado à elevação dos índices de violência e criminalidade em nosso País (Brasil, 2005a; Romani, 2003; Ronzani, Fernandes, Gebara, Oliveira, Scoralick, \& Lourenço, 2009; Minayo \& Deslandes, 1998; Vedovatto, 2010).

O uso de drogas, entretanto, é uma prática antiga e universal, pois pode ser fonte de interesse, atração e medo, entre outros sentimentos e significados culturais que as mesmas provocam nos indivíduos. Assim, dependendo do momento histórico e da cultura predominante de cada época, o uso de drogas pode ser encarado de diversas maneiras, sendo visto, algumas vezes, ora como um problema ou doença, ora como uma solução, ou mesmo como cura (Bucher, 1992).
No início da década de 80, pesquisadores americanos descreveram uma nova e potente forma de uso de cocaína - a inalação do vapor expelido da queima de pedras, produzidas a partir do cozimento da pasta base combinada com bicarbonato de sódio (Kessler \& Pechansky, 2008). O nome crack tem uma origem curiosa. Quando queimada em um cachimbo de vidro ou qualquer outro recipiente, a pedra produz um ruído típico de estalo, produz o som da palavra crack, o que deu origem ao seu nome (Horta, Rodrigues, Lodi, Ribeiro, Wolff, \& Kichler, 2009).

A história do crack no Brasil seguiu uma trajetória semelhante a dos Estados Unidos, porém com um atraso de aproximadamente 10 anos. Os primeiros relatos sobre o consumo de crack surgiram em 1989, entre crianças que viviam nas ruas do centro de São Paulo (Horta et al., 2009). Hoje a mídia brasileira tem relatado casos de uso de crack também nas classes média e alta, mas ainda faltam evidências científicas de que esse índice seja alarmante (Kessler \& Pechansky, 2008). Em 2008, foi publicada uma revisão sobre o perfil dos usuários de crack brasileiros, confirmando que realmente a maior parte dos usuários é jovem, de baixa renda e do sexo masculino (Duailib, Ribeiro, \& Laranjeira, 2008).

Um dos primeiros estudos que focou a mídia e sua relação com o crack mostrou que reportagens publicadas em jornais americanos sobre a epidemia do crack eram sensacionalistas, sem embasamento científico e contribuíam para desviar o foco das autoridades de outros problemas sociais mais urgentes (Hartman \& Gollub, 1999). No Brasil, diversos estudos têm mostrado que, nos meios de comunicação, as drogas são consideradas um mal vinculado ao campo jurídico-policial e médico-psiquiátrico e que, invariavelmente, leva os usuários à criminalidade. O discurso antidrogas é apresentado como hegemônico na sociedade atual, tendo como um de seus 
efeitos a ação repressora e a adoção de uma perspectiva exclusivamente biomédicacurativa (Vedovatto, 2010; Marinho, 2005; Ronzani et al. 2009; Noto, Baptista, Faria, Nappo, Galduróz, \& Carlini, 2003; Brasil, 2005a).

Constituiu, dessa forma, objetivo da presente pesquisa realizar a análise crítica de uma série de reportagens intitulada $A$ Epidemia do Crack, veiculadas pela mídia escrita, interpretando a ideologia que, possivelmente, subjaz ao discurso em relação à droga psicotrópica crack. Essa pesquisa faz parte de um projeto maior intitulado Cenários midiáticos/institucionais, relações de poder e representações: desafios atuais na saúde pública (registrado no Gabinete de Projetos sob o $n^{\circ}$ 028411), ancorado no grupo de pesquisa Saúde, Minorias Sociais e Comunicação.

A partir do referencial da Psicologia Social Crítica da Saúde, que implica uma análise das relações de poder imbricadas no campo da saúde e uma ética do cuidado (Roso, 2007), este artigo apresentará, nas seções seguintes, os pressupostos metodológicos - a hermenêutica de profundidade e a análise de conteúdo temática - e a apresentação e discussão das categorias temáticas resultantes da pesquisa. No final do artigo, tecemos algumas considerações sobre os resultados e como estes podem colaborar na construção de novas pautas de discussão nas mídias bem como na construção de outros olhares sobre o tema.

\section{Pressupostos Metodológicos}

A análise ideológica proposta foi realizada com uma amostra de oito reportagens coletadas no jornal Zero Hora, no período de 6 a 13 de julho de 2008, que constituíram uma série especial denominada $A$ Epidemia do Crack (Melo \& Rocha, 2008). Essa série jornalística foi escolhida como foco deste estudo, pois consideramos que ela seja o marco inicial da midiatização do problema do crack no Estado do Rio Grande do Sul. A partir dessa série, o Grupo Rede Brasil Sul (RBS) passou a veicular uma série de reportagens sobre o tema, bem como a campanha Crack Nem Pensar, em 2009.

O referencial metodológico e teórico adotado foi a Hermenêutica de Profundidade (HP) (Thompson, 2007), que é composto por três fases mutuamente interdependentes e complementares: a análise sociohistórica, a análise formal ou discursiva e a interpretação/ reinterpretação. Essas formas de análise são complementares entre si, partes de um processo interpretativo complexo. Parecenos que o caráter inovador da HP, assim como apontam Veronese \& Guareschi (2006), consiste na superação de abordagens tradicionais de ideologia, já que ela não propõe o desvelamento de sentidos, mas invoca a necessidade de propor sentidos, de discuti-los e de desdobrá-los.

Através dessa ferramenta teórica e metodológica, podemos analisar o contexto sociohistórico e espaço-temporal que cerca o fenômeno pesquisado bem como empreender análises discursivas (de conteúdo, semióticas e argumentativas, entre outras) e analisar a ideologia como vertente social, o que confere um caráter potencialmente crítico à pesquisa (Thompson, 2007; Veronese \& Guareschi, 2006). Em nosso trabalho, para o empreendimento da análise discursiva, adotamos a análise de conteúdo temática.

Operacionalmente, a análise temática desdobra-se em três etapas (Minayo, 2010). A primeira, denominada pré-análise, consiste na escolha dos documentos a serem analisados e na retomada dos objetivos iniciais da pesquisa. A pré-análise pode ser decomposta em três tarefas: a leitura flutuante (contato direto e intenso com o material, deixando-se impregnar pelo seu conteúdo), a constituição 
do corpus (a série jornalística A Epidemia do Crack) e a formulação e/ou reformulação dos objetivos (retomada da etapa exploratória, existindo a possibilidade de revisão de rumos interpretativos ou de abertura para novas indagações).

Portanto, na fase pré-analítica, determinamse as unidades de registro ou de significado (unidades que expressam um sentido em si mesmo e em relação ao contexto. Uma unidade de significado pode ser uma palavra, uma frase ou parágrafo, o que importa é que seja um conjunto de proposições que expressem um determinado tema), a unidade de contexto (a delimitação do contexto de compreensão da unidade de significado), os recortes, a forma de categorização e os conceitos teóricos mais gerais que orientarão a análise.

A segunda etapa, denominada exploração do material (Minayo, 2010), consiste em uma operação classificatória cujo objetivo é alcançar o núcleo de compreensão do texto, ou seja, identificadas as unidades de significado, categorias temáticas foram eleitas, englobando e expressando o conteúdo e as mensagens implícitas contidas nos discursos dos grupos. Para isso, "o investigador busca encontrar categorias que são expressões ou palavras significativas em função das quais o conteúdo de uma fala será organizado" (Minayo, 2010, p. 317). Após a categorização, temos a terceira etapa, denominada tratamento dos resultados obtidos e interpretação.

Foram criadas quatro categorias de análise: crack, criminalidade, combate ao crack e família. A cada unidade de análise foi atribuído um título que ilustrasse o conteúdo temático geral da unidade: (1) o crack: epidêmico, avassalador e diabólico, (2) crack e (é) criminalidade: "todo crackeiro é criminoso", (3) o combate ao crack: a ideologia da repressão e (4) a epidemia do crack e as famílias esfareladas. Optamos, entretanto, em apresentar neste artigo apenas as três primeiras unidades, pois elas compõem um conjunto de significados inter-relacionados, e a categoria família necessitaria de maior espaço para discussão, o que será feito em outra oportunidade. As relações de classe e de gênero identificadas não constituem categorias em si mesmas, pois são elas que movimentam as unidades de análise e permitem um olhar crítico sobre as formas simbólicas transmitidas na mídia, e serão discutidas no corpo das unidades de análise estabelecidas.

\section{O crack das formas simbólicas: a análise discursiva da série jornalística a epidemia do crack}

Apresenta-se, a seguir, uma discussão sobre três das categorias elaboradas para compreender o sentido das formas simbólicas. Lembramos que as categorias não são entidades separadas, mas formam um conjunto discursivo que sempre nos remete ao contexto sociohistórico.

\section{O crack: epidêmico, avassalador e diabólico}

Na série em foco, o crack é apresentado como um ser, como algo que tem vida própria e que invade os lares para destruir as famílias. Várias são as definições apresentadas no decorrer das matérias: a droga que escraviza em segundos, que zomba das esperanças de recuperação, que corrói famílias, que mata mais do qualquer outra droga e que afunda dependentes na degradação moral e no crime. O jornal, dessa forma, indica que o sujeito de todas essas ações é o crack, o usuário e/ou o dependente da droga é o objeto. Nesse sentido, observa-se a utilização da estratégia de passivização (Thompson, 2007), que coloca que os sujeitos são passivos, nada podem fazer diante da ameaça de uma nova doença, da epidemia do crack. 
Segundo

Thompson (2007,

p.83), acordos

institucionais

que servem aos

interesses de

alguns indivíduos

são apresentados

como se

servissem aos interesses de

todos, e esses

acordos são vistos

como abertos,

em princípio,

a qualquer um que tenha a habilidade e a tendência de ser neles bem sucedido.
Ao apresentar um estudante, um Juiz de Direito e um médico que caíram na ruína do vício, a matéria do jornal em foco analisado os coloca em uma posição passiva, o que fica ilustrado nas situações que se seguem: o estudante acabou "experimentando sem saber"; o Juiz, depois de ter passado pelo álcool, maconha e cocaína, "foi apresentado" ao crack por um traficante; o médico que passou uma década sucumbindo e voltando do álcool, da maconha e da cocaína, defrontou-se com a "fase final": o crack, ou seja, foi o mundo da favela que invadiu os bairros e lares das classes média e alta, levando o que há de pior no submundo em que os "vileiros e marginais" vivem. Esses trechos evidenciam mais uma vez a estratégia de passivização dos sujeitos, tornando-os vítimas que não tiveram outra opção, afinal, o álcool, a maconha e a cocaína já não os satisfaziam da mesma forma.

Antes de seguirmos para a próxima estratégia identificada, queremos ressaltar os significados da palavra crack, que tem, na língua inglesa, diversos significados: rachadura, defeito, estalo ou a própria droga crack. Esse termo foi utilizado no período da Grande Depressão no fenômeno crack da bolsa de valores, ocorrido em 1929, na cidade de Nova lorque. Milhões de títulos foram colocados à venda sem que aparecessem compradores. Os preços dos títulos desabaram, e, para saldar compromissos, os bancos norteamericanos deixaram de abrir linhas de crédito aos países estrangeiros e passaram a repatriar os capitais que tinham investido no exterior (Mello \& Costa, 2008).

Pode-se dizer, nesse sentido, que a palavra crack é um significante de dois momentos da era moderna: o crack da bolsa de valores e a epidemia do crack. Assim como a bolsa de valores quebrou, sofreu uma rachadura, a droga crack também provoca quebras nas famílias, nos usuários, na sociedade. Ambas as quebras, em diferentes momentos, constituem um ciclo terrível: a crise a alimentar a crise, a droga a alimentar a droga, que alimenta as desigualdades sociais, a criminalidade, a violência estrutural. Com a quebra da bolsa de valores, em um primeiro momento, a sociedade ficou atônita, passiva, sem ação, assim como ficou em relação à epidemia do crack.

Nas reportagens iniciais da série, verifica-se a estratégia de universalização, como podemos observar no seguinte trecho: o crack atingiu o Estado com uma fúria avassaladora e atinge a vida de todos, inclusive a da elite. Ora, através da universalização, segundo Thompson (2007, p.83), acordos institucionais que servem aos interesses de alguns indivíduos são apresentados como se servissem aos interesses de todos, e esses acordos são vistos como abertos, em princípio, a qualquer um que tenha a habilidade e a tendência de ser neles bem sucedido.

Em outras palavras, um acordo, do qual não sabemos quais são as partes envolvidas, define a situação como epidêmica - todos são vulneráveis - e a mídia se encarrega de difundir e alarmar a população, fazendo com que o assunto se torne um interesse de todos, assim como foi o crack da bolsa de valores. A estratégia de universalização se torna ainda mais evidente quando o jornal argumenta que o estigma de droga da periferia não tem mais confirmação na realidade: a pedra rompeu barreiras e atingiu a elite. O crack explodiu na favela por tratar-se de uma droga poderosa, de fácil acesso e de baixo custo. O crack cruzou a fronteira da favela porque é uma droga que tem um alto poder viciante, é uma promessa de efeitos mais vigorosos e atrai usuários que querem experimentar sensações mais fortes, de qualquer classe social.

Quando o problema passa a ser de todos, torna-se mais fácil criar um inimigo comum: o crack. As reportagens nos mostram que é contra o crack que precisamos lutar, ele 
precisa ser expulso do meio social para que a paz volte a triunfar. Para criar esse inimigo, a mídia vale-se de uma estratégia denominada expurgo do outro. Essa estratégia envolve "a construção de um inimigo, seja ele interno ou externo, que é retratado como mau, perigoso e ameaçador e contra o qual os indivíduos são chamados a resistir coletivamente ou a expurgá-lo" (Thompson, 2007, p. 87). A construção do crack como inimigo social, na mídia escrita, parece ter como eixo central o argumento que estabelece uma associação de causa e efeito entre a elevação nos índices de criminalidade e a epidemia do crack (Brasil, 2005a; Ronzani et al., 2009; Minayo \& Deslandes, 1998; Vedovatto, 2010).

Ao contar diferentes histórias, o jornal afirma que as razões que levam ricos e pobres a experimentarem a droga podem até ser diferentes em alguma medida, mas, após o uso, em alguns dias, o crack alinha-os na mesma ruína. A diferença fundamental entre ricos e pobres viciados em crack, segundo a série do jornal, é o montante de dinheiro que cada um tem a perder na droga. Através dessa diferenciação, a série analisada nos induz a pensar que os pobres têm a tendência de se tornarem criminosos mais rapidamente, pois, ao ter um montante de dinheiro menor, terão que roubar de alguém para sustentar seu vício. Da universalização do problema, percebe-se um movimento de diferenciação. Através dessa estratégia, está "a ênfase que é dada às distinções, diferenças e divisões entre pessoas e grupos, apoiando as características que os desunem e os impedem de constituir um desafio efetivo às relações existentes, ou um participante efetivo no exercício do poder" (Thompson, 2007, p. 87).

A matéria intitulada Aprisionados pela Droga apresenta como personagens os usuários C., A. e D. e suas respectivas histórias. A referida matéria apresenta um raciocínio bem claro: desejado, diabólico e maldito, o crack passou os últimos anos impondo derrotas a C., A. e D.; o crack impõe derrotas porque "consome a cabeça" do usuário, "toma o controle" e os deixa com medo e, em consequência, o tratamento não funciona e o número de reinternações é elevado. Com esses argumentos, o jornal dá ênfase aos aspectos fisiológicos do uso do crack, aspectos esses usualmente supervalorizados pelo modelo biomédico-curativo.

O perigo que se corre ao enfatizar mais os elementos fisiológicos é que outros componentes, como os aspectos econômicos, sociais, culturais e bioecológicos, também importantes na compreensão do campo da dependência química, são esquecidos ou pouco valorizados. A complexidade da dependência ao crack exige uma visão abrangente e integrada de ações e serviços de saúde, a promoção à saúde, que deve resgatar uma "concepção da saúde como produção social e busca(r) desenvolver políticas públicas e ações de âmbito coletivo que extrapolem inclusive o enfoque de risco (campo da prevenção)" (Sícoli \& Nascimento, 2003, p.102), incidindo sobre as condições de vida da população e supondo ações intersetoriais.

A análise das escolhas de expressões metafóricas utilizadas pelo jornal também nos ajuda a compreender as estratégias ideológicas discursivas dos meios de comunicação de massa. Conforme a série analisada, $o$ crack impõe derrotas porque sua fissura é avassaladora. A palavra avassaladora aparece inúmeras vezes no decorrer das matérias e merece maior atenção. A palavra vem do verbo avassalar, que, no dicionário Aurélio (Ferreira, 2008), tem cinco significados: 1) tornar vassalo, reduzir a vassalagem, 2) imperar em, dominar, 3) oprimir, vexar, 4) cativar, seduzir, dominar, 5) causar destruição a, arrasar. Os cinco significados do dicionário se aplicam ao caso do crack, conforme apresentado pela mídia. O crack reduz o usuário à vassalagem, domina o organismo do usuário, oprime-o e a sua família, cativa e seduz no momento da fissura e da recaída, 
e causa destruição às famílias, às cidades e aos usuários.

Na Idade Média, o vassalo era aquele que dependia de um senhor feudal, a quem oferecia fidelidade e trabalho em troca de proteção e de um lugar no sistema de produção (Mello \& Costa, 2008). O crack, senhor feudal, estabelece uma relação de dependência com o usuário, o vassalo, tornando-o fiel. Mas qual lugar o usuáriovassalo ocupa no sistema de produção? De qual sistema de produção estamos falando? Hoje o mundo vive o sistema de produção capitalista, do liberalismo (neoliberalismo), que, além de um sistema econômico, é um sistema de produção de identidades, de subjetividades. Ou se está dentro dele ou se está fora, e representar o crack como avassalador reforça uma ideologia de exclusão social.

O lugar que o usuário-vassalo ocupa é o lugar do fora, um lugar de exclusão e marginalização. Conforme o jornal, "há especialistas dizendo que o mínimo necessário para se livrar da droga seriam três anos de tratamento" (o expurgo não somente do crack, mas também do usuário), "ficou inviável para o Município tratar essas pessoas. Cada paciente internado custa $R \$ 1$ mil por mês. Como são raros os que se recuperam, eles estão sempre voltando para receber atendimento". Assim, deduz-se que o custo é alto, inviável, e eles sempre recaem - existe uma relação de fidelidade entre o senhor e seu vassalo.

Enfim, o crack foi apresentado pela série como epidêmico, avassalador e diabólico, uma droga que anula o sujeito que o consome e que, por isso, precisa ser combatida pela sociedade. Na verdade, conforme as matérias, não é o usuário que consome a pedra, é a pedra que consome o usuário. Para dar sequência a sua argumentação, a série acaba naturalizando a relação entre o uso de crack e a criminalidade, como poderá ser visto a seguir.

\section{Crack e (é) criminalidade: "todo crackeiro é criminoso"}

\begin{abstract}
"A violência é movida a crack no Rio Grande do Sul", sentença extraída literalmente da série em foco, nos leva a interpretar que todos os dados e depoimentos apresentados nas matérias parecem ter uma função bem clara: justificar e legitimar o diagnóstico feito em alguns dos bairros mais afetados pela violência no Estado - o crack é o culpado pela violência que assola o Estado, é o combustível da criminalidade.
\end{abstract}

Em resposta a esse diagnóstico, foi desenvolvido o projeto-piloto do Programa de Prevenção da Violência, uma parceria do Piratini e das prefeituras, conforme o jornal. O projeto teve início no ano de 2007, nos bairros em situação de maior gravidade de cinco Municípios que figuravam na lista dos mais violentos. Nos locais em que esse projeto se vinculou, o crack sempre apareceu como o principal fator da violência. A conclusão dos responsáveis é que combater a violência significa combater o crack.

Ao igualar crack e violência, usuário e criminoso, o jornal utiliza uma estratégia ideológica que permeia quase todas as matérias: a naturalização. Através dessa estratégia, "um estado de coisas que é uma criação social e histórica pode ser tratado como um acontecimento natural ou como um resultado inevitável de características naturais" (Thompson, 2007, p. 88), reduzindo a uma simples relação causal o uso de drogas e a violência.

Apesar dos diversos estudos e evidências empíricas associando uso de drogas e violência, há muita incerteza quanto às explicações causais. Uma questão que não está suficientemente explicada é se 
a presença de álcool ou de outras drogas nos eventos violentos permite inferir que elas tenham afetado o comportamento das pessoas envolvidas (Minayo \& Deslandes, 1998), ou seja, não é possível saber se essas pessoas em estado de abstinência não teriam cometido as mesmas transgressões.

Também não é possível definir, a partir das pesquisas empíricas, se o uso de drogas atua como um fator associado a outros, desencadeando comportamentos violentos, ou se é o fator causador (tal como é apresentado nas matérias analisadas). O que é possível inferir, apenas, é que há uma alta proporção de atos violentos quando o álcool ou as drogas estão presentes entre agressores e vítimas (Minayo \& Deslandes, 1998; Martins \& Pillon, 2008).

Deve ficar claro, portanto, o perigo de se estabelecer uma associação direta entre violência e uso de drogas, pois pode estar reforçando a representação social do usuário de drogas como um criminoso (Mota, 2009) e, em consequência, a exclusão de determinados indivíduos ou grupos sociais. Com o estabelecimento de uma relação causal entre uso de drogas e violência, apenas buscamos curas medicamentosas e repressivas para o dependente, em vez de entendermos o processo como algo psicossocial e histórico (Brasil, 2005a; Mota, 2009). Dessa maneira, instituir políticas públicas que promovam saúde fica relegado em segundo plano (Araújo, Gontiès, \& Nunes Jr., 2007; Oliveira, McCallum, \& Costa, 2010).

Ao lado do título da matéria Assassino aos 11 Anos, há um quadro intitulado Os Primeiros Passos para o Crack. Segue um subtítulo, com letras menores, mas destacado em negrito: $O$ envolvimento de crianças com a pedra segue um padrão. O que a matéria denomina padrão é classificado em quatro categorias - as causas, o início, os delitos leves e os delitos graves. As causas se referem a um cenário para que o vício se estabeleça - a combinação entre predisposição e famílias desestruturadas.

Segundo o jornal, o início do uso geralmente acontece por intermédio de algum amigo; depois largam a escola, pedem dinheiro no semáforo, cometem pequenos furtos em casa e a sequência dos acontecimentos se dá de acordo com o drama apresentado anteriormente. Consumindo crack em grande quantidade e movidos por fissuras avassaladoras, os usuários evoluem na escala de delitos, passam a cometer delitos graves - envolvimento com o tráfico, assassinatos, latrocínios, prostituição, etc.

Nessa questão, encontra-se, explicitamente, a estratégia de padronização. Com essa estratégia, "formas simbólicas são adaptadas a um referencial-padrão, que é proposto como um fundamento partilhado e aceitável de troca simbólica" (Thompson, 2007, p. 86). Ao padronizar as relações entre o uso de crack e os contextos de violência, desconsideram-se as particularidades desse uso em determinados grupos sociais. $\mathrm{Na}$ etnografia de rua realizada por Adorno (2008), por exemplo, presenciaram-se crianças e jovens que, embora acabassem de acordar embaixo de uma marquise ou próximo ao meio fio, passavam a gritar e a se referir como violentos e usuários de crack, usando uma estratégia ao mesmo tempo defensiva e de ataque para atemorizar as pessoas que passavam e a assimilar, por efeito reflexivo, o que a mídia divulgava a respeito da droga da qual faziam uso.

A matéria que abre o quinto dia de reportagens especiais sobre a epidemia do crack, intitulada A Morte é o Destino, apresenta os resultados parciais de uma pesquisa realizada na Universidade Federal de São Paulo. A matéria alerta para o fato de que o levantamento completo, um dos poucos do gênero no mundo, só estará concluído no final do ano, 
mas os dados foram antecipados ao Zero Hora para serem incluídos na série $A$ Epidemia do Crack (Melo \& Rocha, 2008). O jornal utiliza os dados da pesquisa para legitimar o argumento de que o crack e o crime são inseparáveis.

De acordo com a matéria do jornal, o estudo, ao longo de 12 anos, acompanhou alguns dos primeiros usuários da droga no País, e descobriu que os destinos mais prováveis para os usuários de crack são a persistência no uso, o crime, prisão e a morte, o que corresponde às representações sociais hegemônicas sobre o uso de drogas - o usuário como pecador, como criminoso e como doente (Mota, 2009; Araújo et al., 2007; Noto et al., 2003; Oliveira et al., 2010). Realizado por pesquisadores da Unifesp, o trabalho investigou o que aconteceu com os 131 "pacientes da pedra", expressão veiculada pelo jornal Zero Hora.

Um dos aspectos dessa pesquisa mais destacado na matéria é a associação clara entre o crack e o crime. Comparados os biênios 1998-1999 e 2005-2006, notouse um aumento expressivo nos índices de prática de atos ilícitos e prisões. Além disso, a violência está por trás da taxa elevada de óbitos. Dos 27 mortos, 16 foram assassinados por motivos como dívidas com traficantes, envolvimento em gangues e conflitos com a polícia. Esses dados, acreditamos, parecem desejar provar que é o crack que alimenta o crime e que provoca o aumento dos índices de violência no Brasil.

A divulgação dessa pesquisa na série de reportagens sobre o crack parece evidenciar as estratégias de racionalização e naturalização (Thompson, 2007). Através da racionalização, "o produtor de uma forma simbólica constrói uma cadeia de raciocínio que procura defender, ou justificar, um conjunto de relações ou instituições sociais, e, assim, persuadir uma audiência de que isso é digno de apoio" (Thompson, 2007, p. 82). O modo como os resultados do estudo foram apresentados pelo jornal leva o leitor a deduzir que todo crackeiro, mais cedo ou mais tarde, se torna criminoso. Naturaliza-se a relação crack e violência, reforçando relações de exclusão, ou seja, relações de dominação.

\section{O combate ao crack: a ideologia da repressão}

As primeiras intervenções do governo brasileiro relativas à atenção ao usuário de drogas datam no início do século XX e foram constituídas pela criação de um aparato jurídico-institucional (Machado \& Miranda, 2007). Esse aparato estabelecia, através de uma série de leis e decretos, o controle do uso e do comércio de drogas e a preservação da segurança e da saúde pública no País, prevendo penas que determinavam a exclusão dos usuários do convívio social. Em 2003, o Ministério da Saúde estabeleceu a Política de Atenção Integral aos Usuários de Álcool e outras Drogas, e reconheceu que houve um atraso histórico do Sistema Único de Saúde no enfrentamento de problemas associados ao consumo de álcool e de outras drogas. A atual política adota uma abordagem não mais comprometida com o controle e a repressão, mas sim, com a redução dos danos e dos prejuízos.

Através de sua Política de Atenção Integral, o Ministério da Saúde "assume de modo integral e articulado o desafio de prevenir, tratar e reabilitar os usuários de álcool e outras drogas como um problema de saúde pública" (Brasil, 2004, p. 9). O projeto propôs a criação de uma rede de atenção integral do Sistema Único de Saúde (SUS), que envolve ações de prevenção, promoção e proteção à saúde, a construção de malhas assistenciais formadas por dispositivos especializados (os Centros de Atenção Psicossocial Álcool/drogas - CAPSad) e não especializados (unidades básicas, programas de saúde familiar e hospitais em 
geral) bem como o estabelecimento de ações intersetoriais (Machado \& Miranda, 2007).

O que observamos é que, no decorrer da série analisada, são apresentados argumentos que favorecem políticas de repressão, em detrimento das políticas de prevenção, de promoção de saúde e de tratamento. No início da série, a presença de um discurso pautado na estratégia de universalização é marcante, pois é afirmado que todos estão suscetíveis à epidemia e que o índice de recuperação, até então, é zero.

A primeira matéria que se refere ao tratamento apresenta clínicas e o que elas têm a oferecer aos pacientes: piscinas, quadras de tênis, suítes individuais com TV, hidroginásticas, caminhadas no parque, academias de ginástica, passeios culturais e, na maioria dessas clínicas, os pacientes não precisam capinar, nem cuidar de hortas e pomares, como acontece em muitos espaços de tratamento. É importante notar que a matéria É Possível Vencer vem acompanhada do Tratamento VIP. A sigla VIP significa: very important person. A forma simbólica veiculada gera o significado de que somente as pessoas muito importantes merecem um tratamento qualificado, com uma ótima infraestrutura e com "a melhor medicina da atualidade".

Mas como definimos quem é e quem não é VIP? Na matéria, fica claro que VIP é aquele que pertence às classes mais favorecidas economicamente. É quem pode pagar por esses serviços. Os viciados pobres, enquanto aguardam leitos, são acorrentados em suas casas, como último recurso de que as famílias dispõem. Como as causas para o uso entre ricos e pobres são apresentadas de modo diferente (os ricos usam por curiosidade, e os pobres porque são pobres, mesmo), justificam-se os tratamentos diferentes (tratamento VIP e não VIP - ou nada VIP), o que evidencia a estratégia de diferenciação
(Thompson, 2007) entre usuários ricos e usuários pobres.

A matéria intitulada Sem Leito, Viciado é Atendido na Fila apresenta a precariedade do Sistema Único de Saúde (SUS). A matéria não cita a existência dos Centros de Atenção Psicossocial Álcool e Drogas (CAPS ad) e de uma rede de saúde mental. A referência única e central é o hospital psiquiátrico. A leitura dessa matéria causa a impressão de uma volta ao modelo hospitalocêntrico, desconsiderando totalmente os ideais do Movimento da Reforma Psiquiátrica. Sem ter como atender todos os dependentes que buscam internação, o hospital começou a oferecer atendimento na própria fila de espera.

Os CAPS, quando eventualmente são apresentados nas reportagens, aparecem como uma possibilidade de reduzir o problema e têm a função de "oferecer atendimento de emergência em horário comercial". Ao reduzir o CAPS a essa função, as matérias ocultam o papel do CAPS na rede de saúde (e a própria rede de saúde) e sua natureza sociohistórica.

Nesse caso, pode-se constatar não a operação de uma estratégia ideológica específica, mas um modo de operação da ideologia mais amplo: a dissimulação. Através da dissimulação, relações de dominação podem ser estabelecidas e sustentadas pelo fato de serem ocultadas, negadas ou obscurecidas (Thompson, 2007), isto é, o SUS e a política de saúde mental são depreciados, já que os viciados precisam ser atendidos na fila, mas a série de reportagens, em momento algum, apresenta os movimentos sociais antimanicomial e da reforma psiquiátrica, ocultando os desafios políticos dos mesmos e as dificuldades estruturais encontradas para que se consiga construir uma rede de saúde que contemple as demandas da população (Vasconcelos, 2010; Cedraz \& Dimenstein, 2005). 
Ao mesmo tempo em que oculta tais informações e um debate mais profundo sobre a política de saúde mental, identificase a operação da estratégia de eufemização, na qual ações, instituições ou relações sociais são descritas de modo a despertar uma valoração positiva (Thompson, 2007). Se o SUS e a atual política de saúde mental (pautada no Movimento da Reforma Psiquiátrica) são retratados de modo negativo, o hospital psiquiátrico ou os leitos de internação são eufemizados, retratados como positivos, como a solução para o problema dos atendimentos nas filas. Os leitos são fundamentais como retaguarda para a rede de saúde mental, mas não se pode apresentálos como a única solução, em detrimento de todos os outros serviços substitutivos da reforma psiquiátrica.

Dissimulação de um lado, eufemização de outro. Com essas duas operações ideológicas, torna-se evidente, mais uma vez, a estratégia denominada diferenciação. Através da diferenciação, como já foi mencionado, a ênfase é dada às distinções, diferenças e divisões entre eles (Thompson, 2007). Primeiramente, o índice de recuperação é considerado zero, mas é possível vencer quando se tem à disposição um tratamento VIP. O índice de recuperação zero parece se referir ao serviço público e gratuito oferecido à população (SUS). A diferenciação, nesse caso, serve para sustentar uma relação de dominação entre o privado e o público, o pago e o gratuito, e, além disso, serve também para sustentar uma relação de dominação entre um modelo de atenção hospitalocêntrico e um modelo de atenção psicossocial. As formas simbólicas transmitidas nessa matéria enfatizam e legitimam a noção de que o privado é sempre melhor que o público.

À medida que se mostra uma rede de saúde precária, que não funciona, legitima-se a necessidade de criar mais leitos e de centralizar os esforços da saúde para a rede hospitalar. Tudo isso foi apresentado pelo jornal para chegar ao ponto central do argumento: a raiz do problema é que o número de leitos hospitalares para dependentes químicos está diminuindo no momento em que o Estado mais necessita deles. A lei antimanicomial, implantada em 1992 no Rio Grande do Sul, previa que a drogadição deixasse de ser tratada em hospitais psiquiátricos e passasse a ocorrer em hospitais gerais. Resultado: hospitais psiquiátricos fecharam vagas, sem que hospitais gerais abrissem novas.

A raiz do problema, nas formas simbólicas em análise, é a reforma psiquiátrica, e, em consequência, a falta de leitos. O que o jornal Zero Hora não coloca em pauta é que a construção de uma rede comunitária de cuidados é fundamental para a consolidação da reforma psiquiátrica. A articulação em rede dos variados serviços substitutivos ao hospital psiquiátrico é crucial para a constituição de um conjunto vivo e concreto de referências capazes de acolher a pessoa em sofrimento mental. Essa rede é maior, no entanto, do que o conjunto dos serviços de saúde mental do Município. Uma rede se conforma na medida em que são permanentemente articuladas outras instituições, associações, cooperativas e variados espaços das cidades, ou seja, a rede de atenção à saúde mental do SUS define-se como de base comunitária (Brasil, 2005; Vasconcelos, 2010; Cedraz \& Dimenstein, 2005).

Entretanto, ao culpabilizar a reforma psiquiátrica pelas dificuldades no atendimento aos usuários de drogas, o jornal utiliza outra estratégia ideológica, denominada eternalização. Através dela, fenômenos sociohistóricos são esvaziados de seu caráter histórico ao serem apresentados como permanentes e imutáveis (Thompson, 2007). Ao ser esvaziado de seu caráter histórico, o Movimento da Reforma Psiquiátrica fica mais vulnerável, pois, da forma como foi 
apresentado nessa série de reportagens, o movimento não é digno de apoio da população, já que é o culpado pela precariedade nos atendimentos aos usuários de crack. Talvez a solução seja expurgá-lo, porque, se o movimento é culpado pela situação precária, ele é um inimigo a ser combatido, assim como o crack.

Através de dados, histórias e depoimentos de profissionais e autoridades, com algumas poucas exceções, as formas simbólicas transmitidas na mídia evidenciam a preferência pela repressão como estratégia no combate ao crack. Esqueceu-se, contudo, de veicular que a atual política de atenção aos usuários de álcool/drogas no Brasil foi considerada um marco teórico-político que rompeu, segundo Machado e Miranda (2007), com abordagens reducionistas, passando a considerar a presença das drogas nas sociedades contemporâneas como um fenômeno complexo, com implicações sociais, psicológicas, econômicas e políticas, e que, portanto, não pode ser objeto apenas das intervenções psiquiátricas e jurídicas nem tampouco de ações exclusivas da saúde pública.

Além disso, a mídia, tendo como função legal informar e educar criticamente os cidadãos (Roso \& Guareschi, 2007), deveria apresentar a epidemia do crack sob o prisma dessa política, regida pelos ideais da reforma psiquiátrica, do SUS e de uma concepção ampliada de redução de danos. A noção de rede e os dispositivos como os CAPSad não receberam o destaque necessário nas matérias. Foram tecidas duras críticas ao SUS e ao atendimento a usuários de álcool e de outras drogas, não com o intuito de promover um debate ou de apresentar a rede de saúde aos leitores, mas de reforçar a ideia de repressão.

Os resultados desta pesquisa, portanto, são consoantes com diversos estudos sobre mídia e drogas (Hartman \& Gollub, 1999; Noto et al., 2003; Marinho, 2005; Ronzani et al., 2009), dentre eles, o estudo realizado pela Agência de Notícias dos Direitos da Infância e do Ministério da Saúde (Brasil, 2005a). Nesse estudo, constatou-se que tratar de drogas na mídia brasileira significa quase sempre tomar como ponto de partida uma relação estreita com a violência urbana, levando o tema a adquirir proporções gigantescas, com reações da mesma ordem, traduzidas em ações cada vez mais repressivas.

Ainda falta à sociedade meios que proporcionem um olhar realista e ponderado sobre o assunto, que evite cair nos estereótipos mais comuns das visões romantizadas ou associadas unicamente à violência. Por causa dessas visões, a sociedade acaba demandando uma política de repressão, e não de saúde. Entendendo que a mídia não apenas registra e reproduz a realidade, mas a cria (Guareschi, 2003), pressupõe-se que são os meios de comunicação que produzem essas visões distorcidas do tema quando estabelecem uma relação causal entre violência e uso de crack, quando acusam a reforma psiquiátrica e a Lei Antimanicomial pelo caos do SUS, quando naturalizam as relações de classe e de gênero e colocam os sujeitos em uma posição passiva.

\section{Considerações Finais}

Diversas estratégias ideológicas foram identificadas ao longo da série de reportagens analisada: universalização, naturalização, diferenciação, expurgo do outro, eternalização, padronização e eufemização, entre outras. Apesar de tratarmos as estratégias de modo separado neste artigo, elas operam em conjunto, de forma complexa, obscurecendo significados importantes para a compreensão do fenômeno em questão. A racionalização presente na série A Epidemia do Crack parte da universalização - todos estão vulneráveis à epidemia do crack - para depois, além de 
estabelecer um inimigo comum (expurgo do outro), mostrar as diferenças e atribuir-lhes uma valoração também diferenciada: entre ricos e pobres, entre o público e o privado, e entre o modelo da reforma psiquiátrica e o modelo hospitalocêntrico. Se o crack é avassalador, é preciso contê-lo, mas, para isso, é preciso conter o próprio usuário acorrentado em casa ou internado em uma instituição, o que é apresentado como a melhor (e talvez a única) solução.

Contudo, não queremos desmerecer a iniciativa do Grupo RBS de divulgar e alertar a população para esse grave problema. Mas o exercício de análise crítica das matérias analisadas pode indicar algumas sugestões para as pautas midiáticas: os desafios políticos da reforma psiquiátrica, as dificuldades estruturais para o bom andamento dos serviços, a perspectiva da redução de danos, a problematização da associação direta entre uso de drogas e violência, entre outros. Tais temas, caso fossem mais veiculados pelas mídias, poderiam colaborar para que a população tivesse uma visão mais realista sobre a questão, desfazendo, aos poucos, estereótipos, preconceitos e noções pejorativas em relação ao uso/usuário de drogas. Mesmo com a não inclusão desses temas nas pautas de discussão midiática, $\mathrm{o}$ presente trabalho pode estimular um olhar e uma leitura crítica das formas simbólicas veiculadas, um olhar diferente para os mesmos fatos.

Conclui-se, então, que as mídias têm colaborado com a criação, o estabelecimento e a manutenção de relações de dominação (Thompson, 2007; Roso \& Guareschi, 2007), como pôde ser constatado na discussão dos resultados deste trabalho. O estudo da ideologia nos possibilita pensar nas maneiras como o sentido mantém relações de dominação entre ricos e pobres e entre homens e mulheres, entre um modelo de saúde e outro, entre o privado (pago) e o público (gratuito) e entre países desenvolvidos e subdesenvolvidos, entre outras. Uma relação de dominação pode ser estabelecida de diversos modos (gênero, classe, raça, etc.), mas nenhum tipo é mais grave que outro. As estratégias ideológicas identificadas nas unidades de análise servem, em alguma medida, para manter relações de dominação e cristalizar ideias, estereotipando os usuários de crack. As relações de dominação identificadas neste trabalho podem estar colaborando com o estabelecimento e/ou manutenção de processos de exclusão, que prejudicam o acesso aos direitos à saúde das pessoas ou grupos excluídos, em função de sua posição e trajetória traçadas em um campo social.

É necessário, entretanto, que se considerem as limitações do presente trabalho, tendo em vista que toda interpretação é parcial e conflitiva e pode, e muitas vezes deve, ter uma reinterpretação - o que sugere o desenvolvimento de outros estudos relativos ao tema, ampliando o debate e uma compreensão mais profunda desses fenômenos. Por fim, cabe ressaltar que as interpretações apresentadas neste trabalho são apenas um ponto de vista, e, se "todo ponto de vista é a vista de um ponto" (Boff, 1997), nossa pesquisa é apenas mais uma releitura, à qual tentamos imprimir novos significados às representações dos usuários de drogas. 


\section{Moises Romanin}

Mestre em Psicologia, com ênfase em Psicologia da Saúde, pelo Programa de Pós-Graduação em Psicologia da UFSM, Rio Grande do Sul - RS - Brasil.

E-mail: moisesromanini@yahoo.com.br

\section{Adriane Roso}

Doutora em Psicologia pela Pontifícia Universidade Católica do Rio Grande do Sul, Professora Adjunta da Universidade Federal de Santa Maria, Rio Grande do Sul - Brasil.

E-mail: psicologia.ufsm@gmail.com

\section{Endereço para envio de correspondência:}

Rua Mal. Floriano Peixoto, 1750, 3o Andar - Sala 317, Santa Maria - Rio Grande do Sul - Brasil. CEP 97015-372

Recebido 28/5/2010, 1a Reformulação 24/8/2011, Aprovado 15/10/2011. 


\section{Referências}

Adorno, R. C. F. (2008). Uso de álcool e drogas e contextos sociais da violência. SMAD, Rev. Eletrônica Saúde Mental Álcool Drog., 4(1), 2-10.

Araújo, L. F. de, Gontiés, B., \& Nunes Júnior, J. (2007). Representações sociais da cocaína: estudo comparativo entre universitários das áreas de saúde e jurídica. Estudos de Psicologia, 24(3), 315-323.

Boff, L. (1997). A águia e a galinha, a metáfora da condição humana (40a ed.). Petrópolis, RJ: Vozes.

Brasil (2005). Ministério da Saúde. Secretaria de Atenção à Saúde. DAPE. Coordenação Geral de Saúde Mental. Reforma psiquiátrica e política de saúde mental no Brasil. Brasília: OPAS. (Documento apresentado à Conferência Regional de Reforma dos Serviços de Saúde Mental: 15 anos depois de Caracas).

Brasil. (2005a). Mídia e drogas: o perfil do uso e do usuário na imprensa brasileira. Brasília: Agência de Notícias dos Direitos da Infância \& Ministério da Saúde.

Brasil (2004). Ministério da Saúde. Secretaria Executiva. Secretaria de Atenção à Saúde. Coordenação Nacional DST/Aids. A política do Ministério da Saúde para a atenção integral a usuários de álcool e outras drogas (2a. ed.). Brasília: Ministério da Saúde.

Bucher, R. (1992). Drogas e drogadição no Brasil. Porto Alegre: Artes Médicas.

Cedraz, A., \& Dimenstein, M. (2005). Oficinas terapêuticas no cenário da reforma psiquiátrica: modalidades desinstitucionalizantes ou não? Mal-estar e Subjetividade, 5(2), 300-327.

Duailib, L. B., Ribeiro, M., \& Laranjeira, R. (2008). Profile of cocaine and crack users in Brazil. Cad. Saúde Pública, 24(4), 545-57.

Ferreira, A. B. H. (2008). Mini Aurélio (7a ed.). Curitiba: Ed. Positivo.

Fonseca, C. (2005). Concepções de família e práticas de intervenção: uma contribuição antropológica. Saúde e Sociedade, 14(2), 50-59.

Guareschi, P. (2003). Os construtores da informação: meios de comunicação, ideologia e ética. Petrópolis, RJ: Vozes.

Hartman, D. M., \& Gollub, A. (1999). The social construction of the crack epidemic in the print media. J. Psychoactive Drugs, 31(4), 423-33.

Horta, R. L., Rodrigues, V. S., Lodi, D., Ribeiro, A. M., Wolff, A., \& Kichler, G. (2009). Drogas \& internet. São Leopoldo, RS: Sinodal.

Kessler, F., \& Pechansky, F. (2008). Uma visão psiquiátrica sobre o fenômeno do crack na atualidade. Rev. Psiquiatria $R S$ 30(2), 96-98.

Machado, A. R., \& Miranda, P. S. C. (2007). Fragmentos da história da atenção à saúde para usuários de álcool e outras drogas no Brasil: da justiça à saúde pública. História, Ciências, Saúde, 14(3), 801-821.

Marinho, M. B. (mar./ago. de 2005). O demônio nos "paraísos artificiais": considerações sobre as políticas de comunicação para a saúde relacionadas ao consumo de drogas. Interface - Comunic., Saúde, Educ., 9(17), 343-54.

Martins, M. C., \& Pillon, S. C. (2008). A relação entre a iniciação do uso de drogas e o primeiro ato infracional entre os adolescentes em conflito com a lei. Cad. Saúde Pública, 24(5), 1112-1120.

Melo, I., \& Rocha, P. (2008, 6-13 de julho). A epidemia do crack. Zero Hora, Porto Alegre. [Cad. Especial].

Mello, L. I. A., \& Costa, L. C. A. (2008). História geral e do Brasil. São Paulo: Scipione.

Mídia, Porto. (2009, 31 de jan.). Crack nem pensar. Zero Hora, Porto Alegre. (Caderno Economia).

Minayo, M. C. de S. (2010). O desafio do conhecimento pesquisa qualitativa em saúde (12a ed.). São Paulo: Ed. Hucitec.

Minayo, M. C. S., \& Deslandes, S. F. (1998). A complexidade das relações entre drogas, álcool e violência. Cad. Saúde Pública, $14(1), 35-42$.

Mota, L. (2009). Dependência química e representações sociais - pecado, crime ou doença? Curitiba: Juruá Ed.

Noto, A. R., Baptista, M. C., Faria, S. T., Nappo, S. A., Galduróz, J. C. F., \& Carlini, E. A. (2003, jan./fev.). Drogas e saúde na imprensa brasileira: uma análise de artigos publicados em jornais e revistas. Cad. Saúde Pública, 19(1), 69-79.

Oliveira, J. F. de, McCallum, C. A., \& Costa, H. O. G. (2010, jan./fev.). Representações sociais de agentes comunitários de saúde acerca do consumo de drogas. Rev. ESC. Enferm. USP, 44(3), 611-8.

Romani, O. (2003). Informação sobre drogas: ações, valores e orientações (M. Baptista, Trad.). In M. Baptista, M. S. Cruz \& R. Matias. (Orgs.), Drogas e pós-modernidade - faces de um tema proscrito (Vol.2). Rio de Janeiro: EdUERJ.

Ronzani, T. M., Fernandes, A. G. B., Gebara, C. F. de P., Oliveira, S. A., Scoralick, N. N., \& Lourenço, L. M. (2009). Mídia e drogas: análise documental da mídia escrita brasileira sobre o tema entre 1999 e 2003. Ciência \& Saúde Coletiva, 14(5), 1751-1762.

Roso, A. (2007). Psicologia social da saúde: tornamo-nos eternamente responsáveis por aqueles que cativamos. Alethéia, 26, 80-94.

Roso, A., \& Guareschi, P. A. (2007). Megagrupos midiáticos e poder: construção de subjetividades narcisistas. Política \& Trabalho, 26, 37-54

Sícoli, J. L., \& Nascimento, P. R. (2003). Promoção de saúde: concepções, princípios e operacionalização. Interface Comunic., Saúde, Educ., 7(12), 101-122.

Thompson, J. B. (2007). Ideologia e cultura moderna - teoria social crítica na era dos meios de comunicação de massa. Petrópolis, RJ: Vozes.

Vasconcelos, E. M. (2010). Desafios políticos no campo da saúde mental na atual conjuntura: uma contribuição ao debate da IV Conferência Nacional. In E. M. Vasconcelos (Org.), Desafios políticos da reforma psiquiátrica brasileira. São Paulo: Ed. Hucitec.

Vedovatto, S. M. A. (2010). Contrapondo o discurso midiático sobre drogas - nem tão feios, nem tão sujos, nem tão malvados: pessoas de bem também usam drogas! In L. M. B. Santos (Org.), Outras palavras sobre o cuidado de pessoas que usam drogas. Porto Alegre: Ideograf/Conselho Regional de Psicologia do Rio Grande do Sul.

Veronese, M. V., \& Guareschi, P, A. (2006, mai./ago.). Hermenêutica de profundidade na pesquisa social. Ciências Sociais Unisinos, 42(2), 85-93. 